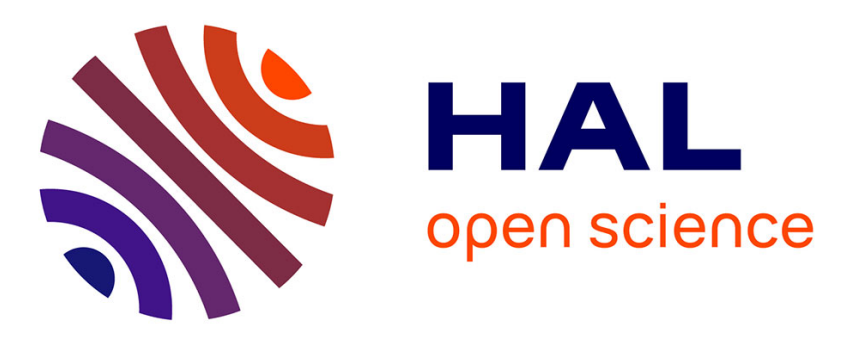

\title{
A novel minimal motif for left-handed G-quadruplex formation
}

Poulomi Das, Fernaldo Richtia Winnerdy, Arijit Maity, Yves Mechulam, Anh Tuân Phan

\section{- To cite this version:}

Poulomi Das, Fernaldo Richtia Winnerdy, Arijit Maity, Yves Mechulam, Anh Tuân Phan. A novel minimal motif for left-handed G-quadruplex formation. Chemical Communications, 2021, 57 (20), pp.2527-2530. 10.1039/d0cc08146a . hal-03188419

HAL Id: hal-03188419

https://hal-polytechnique.archives-ouvertes.fr/hal-03188419

Submitted on 2 Apr 2021

HAL is a multi-disciplinary open access archive for the deposit and dissemination of scientific research documents, whether they are published or not. The documents may come from teaching and research institutions in France or abroad, or from public or private research centers.
L'archive ouverte pluridisciplinaire HAL, est destinée au dépôt et à la diffusion de documents scientifiques de niveau recherche, publiés ou non, émanant des établissements d'enseignement et de recherche français ou étrangers, des laboratoires publics ou privés. 


\title{
A novel minimal motif for left-handed G-quadruplex formation
}

\author{
Poulomi Das, ${ }^{a}$ Fernaldo Richtia Winnerdy, ${ }^{\mathrm{a}, \mathrm{b}}$ Arijit Maity, ${ }^{\mathrm{a}}$ Yves Mechulam, ${ }^{\mathrm{c}}$ and Anh Tuân Phan*a,b
}

Received 00th January 20xx, Accepted 00th January 20xx

DOI: $10.1039 / x 0 x x 00000 x$

\begin{abstract}
A recent study on the left-handed G-quadruplex (LHG4) DNA revealed a 12-nt minimal motif GTGGTGGTGGTG with the ability to independently form an LHG4 and to drive an adjacent sequence to LHG4 formation. Here we have identified a second LHG4-forming motif, GGTGGTGGTGTG, and determined the X-ray crystal structure of an LHG4 involving this motif. Our structural analysis indicated the role of split guanines and single thymine loops in promoting LHG4 formation.
\end{abstract}

G-quadruplex (G4) is one of the non-canonical structures of nucleic acids with growing interest owing to its role in important cellular activities, ${ }^{1-4}$ nanotechnology, ${ }^{5,6}$ as well as therapeutic applications. - $11^{\mathrm{G} 4}$ is constructed from stacked planar tetrads of guanine bases which form Hoogsteen hydrogen bonds between themselves. ${ }^{12}$ These structures are stabilized by metal cations which reside at the centre of the tetrads or in between two stacked tetrads. ${ }^{13-15}$ Polymorphism is a remarkable feature of these multi-layered structures which have been intensively studied in the last few decades. ${ }^{16-21} \mathrm{G} 4$ structures can adopt various conformations depending on the sequences, ${ }^{22-26}$ chemical modifications, ${ }^{27-34}$ ionic conditions, ${ }^{35-37}$ crowding conditions, ${ }^{38-41}$ and others. ${ }^{42-45}$ The diversity is mainly attributed to its structural elements such as loops, strand orientations, and stoichiometry. ${ }^{16-21}$ One of the structural features of G4 is the helicity, which was solely observed to be right-handed, until the first left-handed G4 (LHG4) DNA structure was reported in $2015 .{ }^{46}$ In that study, a DNA sequence derived from the aptamer $A G R O 100,{ }^{8}$ known as Z-G4, displayed left-handed helicity in a G4 structure, ${ }^{46}$ revealing a new class of $\mathrm{G} 4$ structures. Since then, there have been studies reporting on the structure,

\footnotetext{
School of Physical and Mathematical Sciences,

Nanyang Technological University, Singapore 637371 (Singapore)

b. NTU Institute of Structural Biology,

Nanyang Technological University, Singapore 636921 (Singapore)

Laboratoire de Biologie Structurale de la Cellule (BIOC),

Ecole Polytechnique, CNRS-UMR7654, Institut Polytechnique de Paris, Palaiseau 91128 (France)

Electronic Supplementary Information (ESI) available, see DOI: 10.1039/x0xx00000x
}

interaction, and optical properties of LHG4 DNA, ${ }^{47-52}$ but its sequence dependency has not been fully understood.

A 12-nt sequence, Motif1 (GTGGTGGTGGTG, formerly designated as Block2 $\Delta$ ) was discovered previously. It has the ability to form an LHG4 structure independently, as well as drive several sequences to form a left-handed conformation when attached to it. ${ }^{49}$ Herein, in search for other minimal motifs, a systematic study was performed which led to the discovery of yet another minimal motif designated as Motif2, expanding the repertoire of LHG4 forming sequences.

Various 12-nt sequences were systematically designed based on the nature of Motif1,49 as summarized in the following rules: they contain three tracts of double-guanines $\left(3 \mathrm{xG}_{2}\right)$ and two single-guanines $\left(2 \mathrm{XG}_{1}\right)$ separated by four single-thymine $(T)$ residues (Table 1 ). It was previously reported that double-T residues in the loop were not compatible for the formation of LHG $4 \mathrm{~s}^{50}$ and hence single-T loops were strictly used. All the 10 possible DNA sequences were examined by Nuclear Magnetic Resonance (NMR) and Circular Dichroism (CD) spectroscopy. In the one-dimensional (1D) ${ }^{1} \mathrm{H}$ NMR spectra (Figure S1), all sequences displayed imino proton peaks in the $10.5-12.5 \mathrm{ppm}$ range, suggesting the formation of G4 structures. Upon checking CD spectra of these sequences (Figure S2), only two sequences, SG15 (Motif1) and SG45 (Motif2), displayed the LHG4-characteristic CD profile with a positive peak at $245 \mathrm{~nm}$ and a negative peak at $265 \mathrm{~nm} .{ }^{46,49}$ Furthermore, the newly identified Motif2 sequence showed a clean and well-resolved NMR spectrum with eight imino protons (Figure 1B). Thus, Motif2 was chosen for further study.

Table 1. Possible 12-nt sequences with three $G_{2}$ tracts and two single guanines (underlined) at various positions, separated by single thymine residues.

\begin{tabular}{cc|cc}
\hline Name & Sequence $\left(5^{\prime}-3^{\prime}\right)$ & Name & Sequence $\left(5^{\prime}-3^{\prime}\right.$ ) \\
\hline SG12 & GTGTGGTGGTGG & SG24 & GGTGTGGTGTGG \\
SG13 & GTGGTGTGGTGG & SG25 & GGTGTGGTGGTG \\
SG14 & GTGGTGGTGTGG & SG34 & GGTGGTGTGTGG \\
SG15 (Motif1) & GTGGTGGTGGTG & SG35 & GGTGGTGTGGTG \\
SG23 & GGTGTGTGGTGG & SG45 (Motif2) & GGTGGTGGTGTG \\
\hline
\end{tabular}


All previously reported LHG4s formed four-layered structures by stacking two blocks of two-layered G4s, either in dimeric or monomeric conformations.46, 49 To probe the possible formation of a similar four-layered topology by Motif2, the sequence $2 x$ Motif2 was designed, where two Motif2 sequences were connected by a TT linker (Figure 1A). The respective dimeric and monomeric nature of Motif 2 and $2 x$ Motif2 were confirmed in a gel electrophoresis experiment, where the two bands were found to migrate similarly to a fourlayered LHG4 control (Figure S3). The $1 \mathrm{D}^{1} \mathrm{H}$ NMR spectrum of 2xMotif2 showed sixteen imino proton peaks in the 10.5-12.0 ppm region (Figure $1 B$ ), consistent with the formation of a fourlayered G4 structure. The CD spectrum of 2xMotif2 displayed a similar profile to that of Motif2 (Figure 1C) but with approximately two-fold enhanced signal, supporting the mono/dimeric relationship. In UV melting experiments, Motif2 exhibited a two-step unfolding, while $2 x$ Motif2 showed a singlestep melting profile, with Motif2 displaying a higher melting temperature $\left(T_{m}, 64.7^{\circ} \mathrm{C}\right)$ as compared to $2 x$ Motif2 $\left(T_{m}, 47.7^{\circ} \mathrm{C}\right)$ (Figure S4).

To obtain the high-resolution structure, the sequence 2xMotif2 was folded in presence of $\sim 100 \mathrm{mM} \mathrm{K}^{+}$and crystallized. The $\mathrm{X}$-ray diffraction data from the crystal of 2xMotif2 scattered up to a resolution of $1.69 \AA$ and was identified to have $\mathrm{P} 2{ }_{1}$ space group. The anisotropic nature of the data beyond $2.1 \AA$ resulted in low completion in the highresolution spherical bins, hence, necessary anisotropic truncation was done in STARANISO (from Global Phasing Ltd). ${ }^{53}$ The structure was solved with molecular replacement with a resolution limit of $2.0 \AA$. Several rounds of refinements and model buildings were done with the resolution cutoff of $2.0 \AA$. The quality of the electron density map was improved after inclusion of the high-resolution data up to $1.69 \AA$ (Figure S5). The asymmetric unit consists of two non- crystallographic (NCS)- related copies (designated as molecule A and molecule B hereafter, Figure S6). Molecule B has a comparatively higher Bfactor values for certain thymine residues than molecule $A$, which is reflected by the slightly better quality of the map

A 2xMotif2: 5'-GGTGGTGGTGTG TT GGTGGTGGTGTG-3'

B

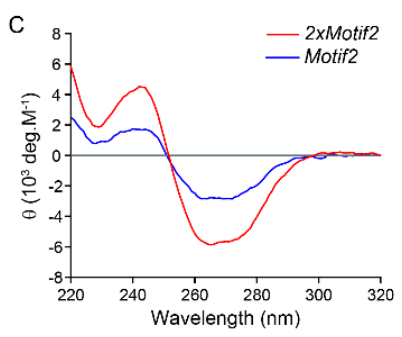

Figure 1. A) The DNA sequence of $2 x$ Motif2 consisting of two Motif2 fragments connected by a TT linker. B) $1 \mathrm{D}^{1} \mathrm{H}$ NMR spectra of $2 x$ Motif2 and Motif2 showing sixteen and eight imino proton peaks, corresponding to the four-layered monomeric and dimeric G4 structures, respectively. C) CD spectra of $2 x$ Motif2 and Motif2.
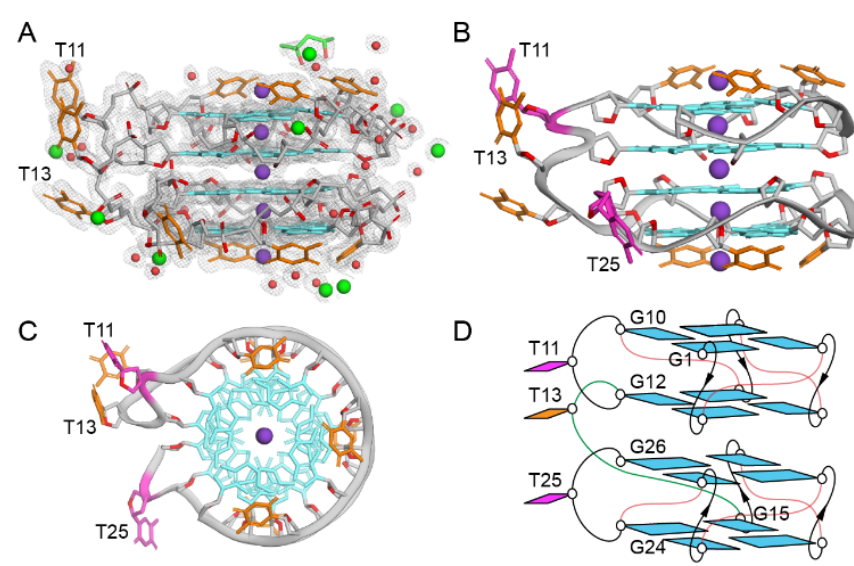

Figure 2. A) X-ray crystal structure of $2 x$ Motif2 with the final electron density map contoured at $1.0 \sigma$. Water molecules are represented by red spheres, strontium ions green and potassium ions - purple. Few water molecules were removed for clarity. B) Side and C) top views of the $2 x$ Motif2 structure highlighting the bulges (T11/T25) in magenta and T-cappings and linkers in orange. D) Schematic of $2 x$ Motif2 highlighting the unique features.

around molecule $A$. The data collection and refinement statistics are presented in Table 2.The structure of $2 x$ Motif2 (Figure 2, PDB ID: 7DFY) reveals a four-layered LHG4 structure.

The structure is composed of two bi-layered blocks connected by a TT linker, similar to previously solved LHG4 structures. ${ }^{46,} 49,50$ Distinct presence of five $\mathrm{K}^{+}$ions with occupancy 1.0 was observed, with three $\mathrm{K}^{+}$ions located in between the four tetrads and the other two seated between the outer tetrads and the capping-thymine layers (Figure 2A). Note that the two $\mathrm{K}^{+}$ions near the capping layers were not found in the analogue structure of $2 x$ Motif1. 49

The thymine capping (T-capping) feature is preserved in all previously reported LHG4s as well as in the 2xMotif2 structure. Interestingly, due to the nature of the crystal packing, two different T-capping conformations were observed. In molecule $A$, the top $T$-capping layer consists of three internal and one external T-loops (T3A, T6A, T9A, T25B), while the bottom Tcapping layer only contains three internal T-loops (T17A, T20A, T23A) (Figure S7A). In contrast, the top T-capping layer of molecule $B$ harbours three internal and one external T-loops (T3B, T6B, T9B, T13A), while the bottom T-capping layer incorporate all four internal T-loops (T14B, T17B, T20B, T23B) (Figure S7B). The thymine linker T14A does not cap in molecule $A$, as it aids to the crystal packing instead (Figure S8).

Bulges (T11 and T25) formed between two stacking guanines G10/G12 and G24/G26, represent novel structural elements (Figure 2B-D). One bulging thymine (T11) is stacked onto a thymine in the linker (T13) giving rise to a unique structural aspect. Assuming a similar folding topology in the dimeric Motif2 structure, the presence of a bulge in each of the dimeric component could potentially cause a specific stacking preference at the interface, resulting in eight clean imino proton peaks in the NMR spectrum. In contrast, the dimeric Motif1 structure in solution might have multiple stacking modes at the interface, producing many imino proton peaks in the spectrum (Figure S1). ${ }^{49}$ 
Table 2. Data collection and refinement statistics of $2 x$ Motif2 structure

\begin{tabular}{|c|c|c|}
\hline \multicolumn{3}{|c|}{ Data collection and anisotropic data analysis with STARANISO ${ }^{53}$} \\
\hline & Spherical & Ellipsoidal** \\
\hline Wavelength ( $\AA$ ) & 0.95373 & 0.95373 \\
\hline Space group & $\mathrm{P} 2{ }_{1}$ & $\mathrm{P} 22_{1}$ \\
\hline Unit cell ( $(\AA /$ deg) & 28.40531 .601 & 28.40531 .601 \\
\hline & 77.7649098 .067 & 77.7649098 .067 \\
\hline & 90 & 90 \\
\hline Resolution range & $38.5-1.69(1.751-$ & $76.995-1.69$ \\
\hline & 1.69) & $(1.904-1.69)$ \\
\hline Total reflections & $17879(42)$ & $57187(1587)$ \\
\hline Unique reflections & $9009(23)$ & $9010(450)$ \\
\hline Multiplicity & $2.0(1.8)$ & $6.3(3.5)$ \\
\hline Completeness (\%) & $57.70(1.49)$ & $86.2(40.5)$ \\
\hline Mean I/sigma(I) & 8.30 (1.09) & $8.0(1.0)$ \\
\hline Wilson B-factor & 11.99 & 11.99 \\
\hline R-merge & $0.1217(0.5685)$ & $0.189(1.212)$ \\
\hline R-meas & $0.1721(0.804)$ & $0.206(1.426)$ \\
\hline R-pim & $0.1217(0.5685)$ & $0.080(0.739)$ \\
\hline $\mathrm{CC} 1 / 2$ & $0.98(0.384)$ & $0.996(0.349)$ \\
\hline \multicolumn{3}{|c|}{ Refinement statistics ${ }^{54}$} \\
\hline Resolution range & & $-1.69(1.93-1.69)$ \\
\hline $\begin{array}{l}\text { Reflections used in } \\
\text { refinement }\end{array}$ & & $8993(582)$ \\
\hline Reflections used for R-free & & $437(21)$ \\
\hline R-work & & $0.2010(0.2968)$ \\
\hline R-free & & $0.2589(0.3988)$ \\
\hline \multicolumn{3}{|c|}{ Number of atoms } \\
\hline DNA & & 1098 \\
\hline $\mathrm{K}^{+}$ & & 11 \\
\hline $\mathrm{Sr}^{+2}$ & & 10 \\
\hline MPD & & 8 \\
\hline Water & & 80 \\
\hline Average B-factor of $\left(\AA^{2}\right)$ & & 20.9 \\
\hline DNA & & 21.2 \\
\hline $\mathrm{K}^{+}$ & & 31.7 \\
\hline $\mathrm{Sr}^{+2}$ & & 25.8 \\
\hline MPD & & 20.7 \\
\hline Water & & 16.4 \\
\hline \multicolumn{3}{|l|}{ Rmsd } \\
\hline Bond angles, $\left({ }^{\circ}\right)$ & & 1.03 \\
\hline Bond length, $(\AA)$ & & 0.008 \\
\hline Clashscore & & 2.3 \\
\hline Number of TLS groups & & 2 \\
\hline
\end{tabular}

Statistics for the highest-resolution shell are shown in parentheses.

Diffraction limits [A] 1.6751 .8082 .403

**Eigenvector-1 0.9710 .0000 .237 Direction-1 0.963 _a_ ${ }^{*}+0.268$ _c_

Eigenvector-2 0.000 1.000 0.000 Direction-2_b_*

Eigenvector-3 -0.2370 .0000 .971 Direction-3 -0.087 _a_* +0.996 _c *

In terms of sequence termini and inter-block linkers, we noticed a difference between the structures of $2 x$ Motif1 and 2xMotif2. The 5' terminus of 2xMotif1 structure was in an inner tetrad and the $3^{\prime}$ terminus was exposed in an outer tetrad, with the TT linker connecting the first and the third tetrads (Figure 3A). ${ }^{49}$ Contrastingly, in $2 x$ Motif 2 structure, the $5^{\prime}$ and 3 ' termini were in an outer and inner tetrad respectively, with the TT linker connecting the second and the fourth tetrads (Figure 3B). This observation provides a sequence-to-topology relationship that could be exploited for engineering LHG4 structures.
The overall structures of both 2xMotif1 and 2xMotif2 were analogous (Figure 3 ), which helps to understand the underlying sequence parameters that drive their formations. In 2xMotif2, two stacking-guanine pairs were split by a $\mathrm{T}$ bulge each. This extends the definition of split guanine requirement, wherein the guanines can be split by a chain of 10 residues (in Motif1) or by a single residue (in Motif2) (Figure 3). The other previously constructed requirement of LHG4 formation was the strict single T-loop rule, where an increase of the loop length even by one residue was shown to be incompatible for LHG4 formation. ${ }^{50}$ Herein, the Motif2 and $2 \times$ Motif2 sequences comply with this requirement, with all the G-tracts and split Gs separated by single T residues, except for the inter-block linker.

Motif2 is the second 12-nt sequence (the first being Motif1) which can independently form an LHG4 structure. Previously, Motif1 was shown to alter the structure of certain sequences upon their attachment with it. ${ }^{49}$ For instance, the sequence $T B$ (GGTGGTGGTGG, Table S1) which forms a right-handed G4 structure on its own was converted into a left-handed G4 when attached with Motif1.46, 49 To probe the driving capability of Motif2, it was subjected to a similar test wherein it was attached with the sequence TB (Table S1). Motif2 was able to partially drive the formation of an LHG4 upon attachment to $T B$ as indicated by $1 \mathrm{D}{ }^{1} \mathrm{H}$ NMR and CD spectra of TB-Motif2 (Figure S9). These results suggest that Motif2 possesses some LHG4 driving ability, albeit less powerful than that of Motif1, indicated by the presence of residual right-handed signals in both its $1 \mathrm{D}$ ${ }^{1} \mathrm{H}$ NMR and CD spectra. Both Motif1 and 2xMotif1 displayed similar melting profiles with Motif2 and 2xMotif2, respectively, with the former sequences exhibiting higher melting temperatures than the latter (Figure S10). The decrease in the thermal stability of Motif 2 and its counterpart is possibly due to the formation of bulges.

In conclusion, a second minimal motif (Motif2) for lefthanded G4 formation was identified. The X-ray crystal structure of $2 x$ Motif 2 provides insights and clarification on the essential and auxiliary features of left-handed G4s. A structural analysis and comparison with the previous minimal motif (Motif1) revealed several constitutive features such as the presence of split guanines and T-cappings, as well as several variative features such as the presence of bulges and the localization of the sequence termini in the structures.

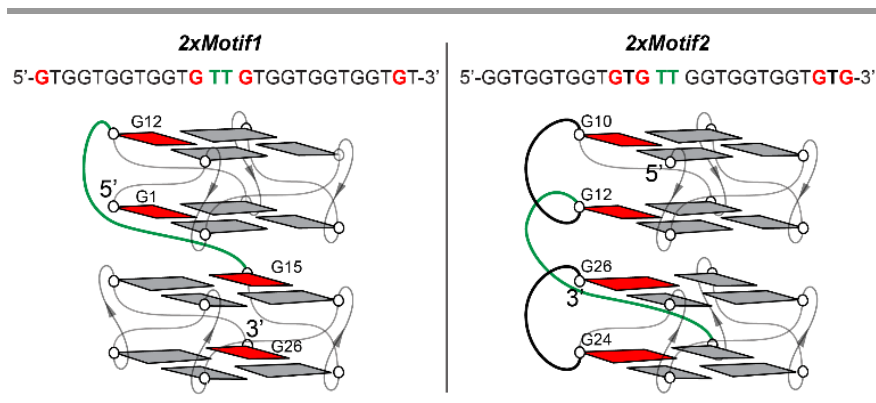

Figure 3. Schematics of the $2 x$ Motif 1 and $2 x$ Motif 2 structures. The split guanines are highlighted in red, the linkers in green and the bulges in boldface black. Black arrows indicate $5^{\prime}$ to $3^{\prime}$ directionality in the structures. 
This work was supported by the Singapore National Research Foundation Investigatorship (NRF-NRFI2017-09) and Ministry of Education Academic Research Fund Tier 2 (MOE2015-T2-1-092). Authors would like to acknowledge the help from Dr. Paul Emsley, Dr. Tom Terwilliger, Dr. Clemens Vonrhein and Dr. Robbie Joosten at the crystallographic school SEA COAST 2020 https://seacoast.kmutt.ac.th/ for their help in solving the crystal structure. We would also like to thank $\mathrm{Dr}$. Chong Wai Liew from NTU Institute of Structural Biology (NISB) and the staffs of MX1 Beamline, Australian Synchrotron for collecting the $\mathrm{X}$-ray diffraction data.

\section{Conflicts of interest}

There are no conflicts to declare.

\section{Notes and references}

1. M. L. Bochman, K. Paeschke and V. A. Zakian, Nat Rev Genet, 2012, 13, 770-780.

2. N. Maizels and L. T. Gray, PLoS Genet, 2013, 9, e1003468.

3. D. Rhodes and H. J. Lipps, Nucleic Acids Res, 2015, 43, 86278637.

4. F. B. Johnson, Annu Rep Med Chem, 2020, 54, 3-44.

5. L. A. Yatsunyk, O. Mendoza and J. L. Mergny, Acc Chem Res, 2014, 47, 1836-1844.

6. J. L. Mergny and D. Sen, Chem Rev, 2019, 119, 6290-6325.

7. D. Monchaud and M. P. Teulade-Fichou, Org Biomol Chem, 2008, 6, 627-636.

8. P. J. Bates, D. A. Laber, D. M. Miller, S. D. Thomas and J. O. Trent, Exp Mol Pathol, 2009, 86, 151-164.

9. S. Balasubramanian, L. H. Hurley and S. Neidle, Nat Rev Drug Discov, 2011, 10, 261-275.

10. G. W. Collie and G. N. Parkinson, Chem Soc Rev, 2011, 40, 5867-5892.

11. S. Neidle, J Med Chem, 2016, 59, 5987-6011.

12. M. Gellert, M. N. Lipsett and D. R. Davies, Proc Natl Acad Sci U S A, 1962, 48, 2013-2018.

13. N. V. Hud, P. Schultze, V. Sklenar and J. Feigon, J Mol Biol, 1999, 285, 233-243.

14. P. Podbevsek, N. V. Hud and J. Plavec, Nucleic Acids Res, 2007, 35, 2554-2563.

15. D. Bhattacharyya, G. Mirihana Arachchilage and S. Basu, Front Chem, 2016, 4, 38.

16. J. T. Davis, Angew Chem Int Ed Engl, 2004, 43, 668-698.

17. S. Burge, G. N. Parkinson, P. Hazel, A. K. Todd and S. Neidle, Nucleic Acids Res, 2006, 34, 5402-5415.

18. D. J. Patel, A. T. Phan and V. Kuryavyi, Nucleic Acids Res, 2007, 35, 7429-7455.

19. J. Dai, M. Carver and D. Yang, Biochimie, 2008, 90, 11721183.

20. A. T. Phan, FEBS J, 2010, 277, 1107-1117.

21. F. R. Winnerdy and A. T. Phan, in Annual Reports in Medicinal Chemistry, ed. S. Neidle, Academic Press, 2020, vol. 54, pp. 45-73.

22. M. Crnugelj, P. Sket and J. Plavec, J Am Chem Soc, 2003, 125, 7866-7871.

23. M. Adrian, B. Heddi and A. T. Phan, Methods, 2012, 57, 1124.

24. M. Marusic and J. Plavec, Angew Chem Int Ed Engl, 2015, 54, 11716-11719.

25. S. A. Dvorkin, A. I. Karsisiotis and M. Webba da Silva, Sci Adv, 2018, 4, eaat3007.
26. A. Maity, F. R. Winnerdy, W. D. Chang, G. Chen and A. T. Phan, Nucleic Acids Res, 2020, 48, 3315-3327.

27. A. T. Phan and D. J. Patel, J Am Chem Soc, 2003, 125, 1502115027.

28. A. T. Phan, V. Kuryavyi, K. N. Luu and D. J. Patel, Nucleic Acids Res, 2007, 35, 6517-6525.

29. M. Webba da Silva, M. Trajkovski, Y. Sannohe, N. Ma'ani Hessari, H. Sugiyama and J. Plavec, Angew Chem Int Ed Engl, 2009, 48, 9167-9170.

30. C. J. Lech, Z. Li, B. Heddi and A. T. Phan, Chem Commun (Camb), 2012, 48, 11425-11427.

31. J. Dickerhoff and K. Weisz, Angew Chem Int Ed Engl, 2015, 54, 5588-5591.

32. V. V. Cheong, C. J. Lech, B. Heddi and A. T. Phan, Angew Chem Int Ed Engl, 2016, 55, 160-163.

33. L. Haase, B. Karg and K. Weisz, Chembiochem, 2019, 20, 985993.

34. L. Haase and K. Weisz, Nucleic Acids Res, 2020, DOI: 10.1093/nar/gkaa720.

35. K. N. Luu, A. T. Phan, V. Kuryavyi, L. Lacroix and D. J. Patel, J Am Chem Soc, 2006, 128, 9963-9970.

36. M. Trajkovski, M. W. da Silva and J. Plavec, J Am Chem Soc, 2012, 134, 4132-4141.

37. K. W. Lim, V. C. Ng, N. Martin-Pintado, B. Heddi and A. T. Phan, Nucleic Acids Res, 2013, 41, 10556-10562.

38. D. Miyoshi, H. Karimata and N. Sugimoto, J Am Chem Soc, 2006, 128, 7957-7963.

39. Y. Xue, Z. Y. Kan, Q. Wang, Y. Yao, J. Liu, Y. H. Hao and Z. Tan, J Am Chem Soc, 2007, 129, 11185-11191.

40. M. C. Miller, R. Buscaglia, J. B. Chaires, A. N. Lane and J. O. Trent, J Am Chem Soc, 2010, 132, 17105-17107.

41. B. Heddi and A. T. Phan, J Am Chem Soc, 2011, 133, 98249833.

42. F. M. Lannan, I. Mamajanov and N. V. Hud, J Am Chem Soc, 2012, 134, 15324-15330.

43. J. Thevarpadam, I. Bessi, O. Binas, D. P. Goncalves, C. Slavov, H. R. Jonker, C. Richter, J. Wachtveitl, H. Schwalbe and A. Heckel, Angew Chem Int Ed Engl, 2016, 55, 2738-2742.

44. P. Shrestha, S. Jonchhe, T. Emura, K. Hidaka, M. Endo, H. Sugiyama and H. Mao, Nat Nanotechnol, 2017, 12, 582-588.

45. S. Jonchhe, S. Pandey, T. Emura, K. Hidaka, M. A. Hossain, P. Shrestha, H. Sugiyama, M. Endo and H. Mao, Proc Natl Acad Sci U S A, 2018, 115, 9539-9544.

46. W. J. Chung, B. Heddi, E. Schmitt, K. W. Lim, Y. Mechulam and A. T. Phan, Proc Natl Acad Sci U S A, 2015, 112, 27292733.

47. B. Fu, J. Huang, Y. Chen, Y. Wang, T. Xue, G. Xu, S. Wang and X. Zhou, Chem Commun (Camb), 2016, 52, 10052-10055.

48. A. Zhao, C. Zhao, J. Ren and X. Qu, Chem Commun (Camb), 2016, 52, 1365-1368.

49. B. Bakalar, B. Heddi, E. Schmitt, Y. Mechulam and A. T. Phan, Angew Chem Int Ed Engl, 2019, 58, 2331-2335.

50. F. R. Winnerdy, B. Bakalar, A. Maity, J. J. Vandana, Y. Mechulam, E. Schmitt and A. T. Phan, Nucleic Acids Res, 2019, 47, 8272-8281.

51. M. Zuffo, A. Gandolfini, B. Heddi and A. Granzhan, Nucleic Acids Res, 2020, 48, e61.

52. S. Daly, F. Rosu and V. Gabelica, Science, 2020, 368, 14651468.

53. I. J. Tickle, Flensburg, C., Keller, P., Paciorek, W., Sharff, A., Vonrhein, C., Bricogne, G. , Journal, 2018.

54. P. D. Adams, P. V. Afonine, G. Bunkoczi, V. B. Chen, I. W. Davis, N. Echols, J. J. Headd, L. W. Hung, G. J. Kapral, R. W. Grosse-Kunstleve, A. J. McCoy, N. W. Moriarty, R. Oeffner, R. J. Read, D. C. Richardson, J. S. Richardson, T. C. Terwilliger and P. H. Zwart, Acta Crystallogr D Biol Crystallogr, 2010, 66, 213-221. 